\title{
PREDIKSI PERGERAKAN HARGA FOREX MENGGUNAKAN METODE NAÏVE BAYES
}

\section{MUHAMMAD ALFAN ALFADILLA}

Teknik Informatika, Fakultas Teknik

Universitas Maarif Hasyim Latif, Sidoarjo, Indonesia

e-mail : muhammad-alfan-alfadilla@student.umaha.ac.id

\begin{abstract}
ABSTRAK
Bagi seorang trader, mengetahui pergerakan harga forex di periode waktu selanjutnya adalah hal yang sangat berguna, maka dibutuhkan teknik untuk melakukan prediksi. Walaupun dalam prediksi ada ketidakpastian yang terjadi karena beberapa faktor yang menyebabkan harga forex bergerak. Algoritma Naïve Bayes adalah algoritma klasifikasi yang mampu untuk melakukan prediksi dan berbasis probabilitas. Dengan mempelajari data yang ada di masa lalu, algoritma ini berusaha untuk melakukan prediksi untuk pergerakan harga di periode waktu selanjutnya sehingga bisa membantu trader untuk mengambil keputusan yang tepat. Data forex yang diolah bersumber dari www.investing.com dari tanggal 11 Desember - 28 Februari 2019. Aplikasi untuk pengolah datanya dibuat dari bahasa PHP. Berdasarkan hasil prediksi untuk bulan Maret yang dilakukan oleh aplikasi yang dibuat, dengan tingkat probabilitas diatas $90 \%$ akan menghasilkan tingkat akurasi 100\%, dengan hasil tersebut diharapkan dapat membantu para trader untuk meminimalisir resiko yang terjadi ketika melakukan open posisi.
\end{abstract}

Kata kunci: prediksi, naïve bayes , forex, php

\section{PENDAHULUAN}

Trading forex adalah kegiatan perdagangan mata uang dari berbagai negara yang berbeda dengan tujuan untuk mendapatkan keuntungan. Sedangkan trader adalah orang yang melakukan kegiatan trading forex. Dalam hal ini, Foreign Exchange atau yang biasa disingkat forex adalah pertukaran mata uang dari berbagai negara/asing atau valuta asing (valas). Transaksi jual-beli mata uang diantara berbagai pihak itu bukan terjadi di sebuah pasar dengan bangunan fisik, melainkan dalam jaringan tak kasat mata yang disebut pasar forex (forex market). Ada beberapa mata uang yang paling popular di pasar forex, yaitu Dollar Amerika (USD), Poundsterling Inggris (GBP), Euro Dollar (EUR), Swiss Franc (CHF), Japanese Yen (JPY), Australian Dollar (AUD), dan Canadian Dollar (CAD) (Saputri, 2016). Mengetahui pergerakan harga forex di masa depan adalah suatu hal yang sangat penting bagi trader. Maka dibutuhkan teknik untuk memprediksi. Proses prediksi harus mengupayakan keakuratan hasil prediksi, meskipun akan ada ketidakpastian dari pergerakan harga forex karena faktor tertentu. Dalam statistika terdapat beberapa metode prediksi (peramalan) yang biasa dilakukan dalam penelitian-penelitian untuk memprediksi masalah pergerakan harga forex yang terjadi di suatu pasar forex. Dalam studi ini, penulis akan menerapkan metode Naïve Bayes Classifier (NBC) untuk memprediksi pergerakan harga forex dengan menggunakan data latih (data training) dari range pergerakan harian masa lampau.

Penulis telah mengamati beberapa penelitian yang relevan, [1] membuat aplikasi berbasis desktop menggunakan Microsoft Visual C\# 2015. Persamaan dengan penelitian ini adalah menggunakan metode yang sama yaitu naïve bayes dan membuat aplikasinya, sedangkan perbedaannya adalah aplikasi yang dibuat oleh penulis berbasis web. Sementara itu [2] persamaan pada penelitian ini adalah menggunakan metode naïve bayes, sedangkan perbedaannya adalah penulis menggunakan forex bukan emas, dan penulis membuat program dan tidak menggunakan program Rapidminer.

Dari latar belakang yang telah dijelaskan, didapat rumusan penelitian ini yang bertujuan menjelaskan proses penghitungan menggunakan metode naïve bayes untuk memprediksi pergerakan harga forex dan untuk menjelaskan tingkat akurasi metode naïve bayes untuk memprediksi pergerakan harga forex.

\section{METODOLOGI PENELITIAN}

\author{
Perancangan Sistem \\ Perancangan yang digunakan untuk \\ merancang sistem ini menggunakan perancangan \\ database, flowchart.

\section{Desain Database} \\ Dalam pembuatan aplikasi ini dibutuhkan \\ desain database untuk menyimpan data yang akan
}


digunakan dalam proses aplikasi. Desain database ini menjelaskan tabel-tabel yang digunakan. Ada 4 tabel yang digunakan dalam aplikasi ini, yaitu tabel data asli, tabel naik, tabel turun, tabel uji.

Tabel 1. Tabel data asli

\begin{tabular}{r|l|l|l|l}
\hline No & Field & Tipe Data & Key & Keterangan \\
\hline 1 & id_data & int(11) & PK & id data \\
\hline 2 & tgl & text & & tanggal \\
\hline 3 & open & double & & harga open \\
\hline 4 & close & double & & harga close \\
\hline 5 & high & double & & harga tertinggi \\
\hline 6 & low & double & & harga terendah \\
\hline 7 & range & double & & range \\
\hline
\end{tabular}

Tabel 2. Tabel naik

\begin{tabular}{r|l|l|l|l}
\hline No & Field & Tipe Data & Key & Keterangan \\
\hline 1 & no & int $(11)$ & PK & Id \\
\hline 2 & a & double & & $\mathrm{x} /$ range \\
\hline 3 & $\mathrm{~b}$ & double & & $\mathrm{x}+1$ \\
\hline 4 & $\mathrm{c}$ & double & & $\mathrm{x}+2$ \\
\hline 5 & $\mathrm{~d}$ & double & & $\mathrm{x}+3$ \\
\hline 6 & $\mathrm{e}$ & double & & $\mathrm{x}+4$ \\
\hline 7 & ket & varchar(5) & & $\mathrm{x}+5$ / kelas \\
\hline
\end{tabular}

Tabel 3. Tabel turun

\begin{tabular}{r|l|l|l|l}
\hline No & Field & Tipe Data & Key & Keterangan \\
\hline 1 & no & int(11) & PK & Id \\
\hline 2 & a & double & & $\mathrm{x} /$ range \\
\hline 3 & $\mathrm{~b}$ & double & & $\mathrm{x}+1$ \\
\hline 4 & $\mathrm{c}$ & double & & $\mathrm{x}+2$ \\
\hline 5 & $\mathrm{~d}$ & double & & $\mathrm{x}+3$ \\
\hline 6 & $\mathrm{e}$ & double & & $\mathrm{x}+4$ \\
\hline 7 & ket & varchar(5) & & $\mathrm{x}+5$ / kelas \\
\hline \multicolumn{5}{|c}{ Tabel 4. Tabel uji } \\
\hline No & Field & Tipe Data & Key & Keterangan \\
\hline 1 & no & int(11) & PK & $\mathrm{Id}$ \\
\hline 2 & $\mathrm{a}$ & double & & $\mathrm{x} /$ range \\
\hline 3 & $\mathrm{~b}$ & double & & $\mathrm{x}+1$ \\
\hline 4 & $\mathrm{c}$ & double & & $\mathrm{x}+2$ \\
\hline 5 & $\mathrm{~d}$ & double & & $\mathrm{x}+3$ \\
\hline 6 & $\mathrm{e}$ & double & & $\mathrm{x}+4$ \\
\hline
\end{tabular}

\section{Flowchart}

Flowchart juga sering disebut dengan diagram alir merupakan suatu jenis diagram yang merepresentasikan langkah-langkah instruksi yang berurutan dalam sistem.

Pada Gambar 1, digambarkan mengenai flowchart dari sistem yang dibuat, dimana dimulai dari upload data, setelah format data yang diupload telah dikoreksi oleh sistem dan dinyatakan benar, kemudian sistem menyimpan file yang diupload. Tahap selanjutnya adalah tahap penyusunan data. Setelah tahap penyusunan data dilakukan, maka akan masuk pada proses selanjutnya yaitu tahap Naïve Bayes. Pada tahap Naïve Bayes ini akan didapat hasil prediksi, tetapi sebelum menampilkan hasil prediksi, dilakukan pengolahan tanggal dahulu untuk kemudian ditampilkan juga pada hasil prediksi. Setelah proses pengolahan tanggal selesai, maka masuk pada tahap akhir, yaitu menampilkan output hasil prediksi.

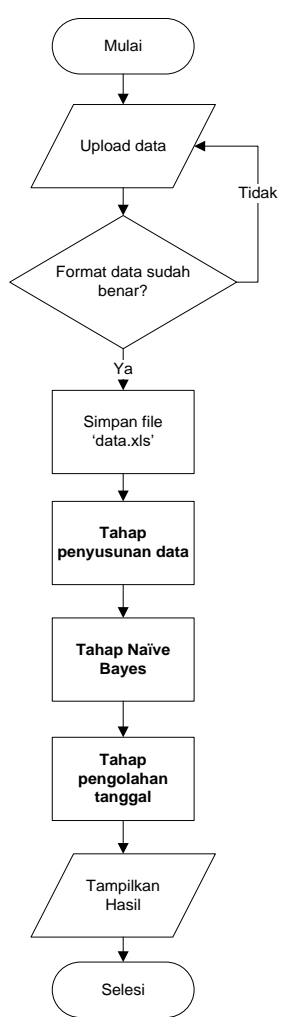

Gambar 1. Flowchart sistem keseluruhan

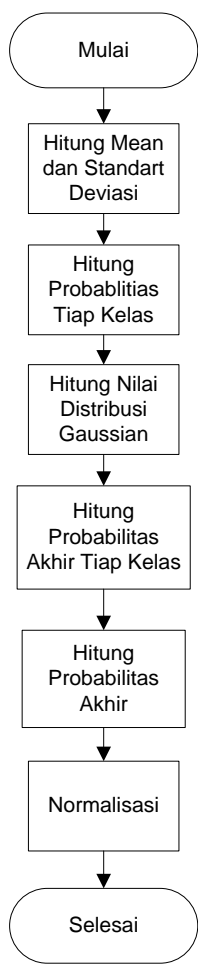

Gambar 2. Flowchart Tahap Naïve Bayes

Pada Gambar 2, digambarkan mengenai flowchart dari tahap Naïve Bayes atau algoritma Naïve Bayes. Dimulai dari proses hitung untuk mencari nilai mean dan standart deviasi pada setiap kelasnya. Selanjutnya adalah mencari nilai probablitas setiap kelas. Setelah itu, dilanjutkan untuk mencari nilai distribusi Gaussian, kemudian 
menghitung probabilitas akhir tiap kelas. Selanjutnya adalah menghitung probabilitas akhir dan melakukan normalisasi.

Pada Gambar 3, digambarkan mengenai flowchart dari detail tahap penyusunan data, yaitu dimulai dari insert DB atau memasukkan data yang berada di file excel yang telah disimpan di server ke database sistem. Proses selanjutnya yaitu, menyusun data latih berdasarkan kelasnya, jika data yang disusun termasuk pada kelas naik, maka akan dimasukkan ke tabel naik, setelah sebelumnya dilakukan transformasi terlebih dahulu. Setelah proses penyusunan data latih, ada proses penyusunan data uji, proses ini sama seperti penyusunan data latih, hanya saja pada proses ini, data yang telah disusun dimasukkan pada tabel uji setelah dilakukan proses transformasi.

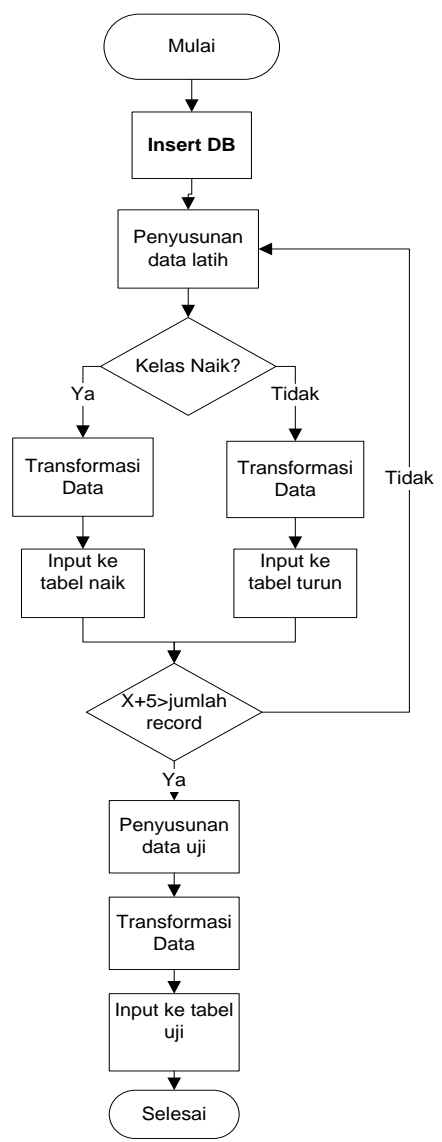

Gambar 3. Flowchart Tahap penyusunan data

Pada Gambar 4, digambarkan mengenai detail flowchart dari insert DB. Insert DB maksudnya adalah memasukkan data yang ada di dalam file excel yang disimpan di server, ke dalam database (DB). Proses ini dimulai dari menghitung jumlah baris yang ada isinya di dalam file excel, kemudian mengambil data yang berda pada baris ke-X, disini X nilainya dimulai dari 2 bukan 1 , karena di baris 1 hanya berisi keterangan kolom data. Setelah data diambil, data diuji apakah data Range-nya bernilai 0 , apakah data ke-X adalah hari
Sabtu atau Minggu. Jika ada data memenuhi ketiga syarat tersebut, maka data tidak akan diinput, tetapi jika tidak memenuhi, maka data akan diinput kedalam database. Proses tersebut akan diulang sampai nilai X lebih besar dari jumlah baris yang telah dihitung sebelumnya.

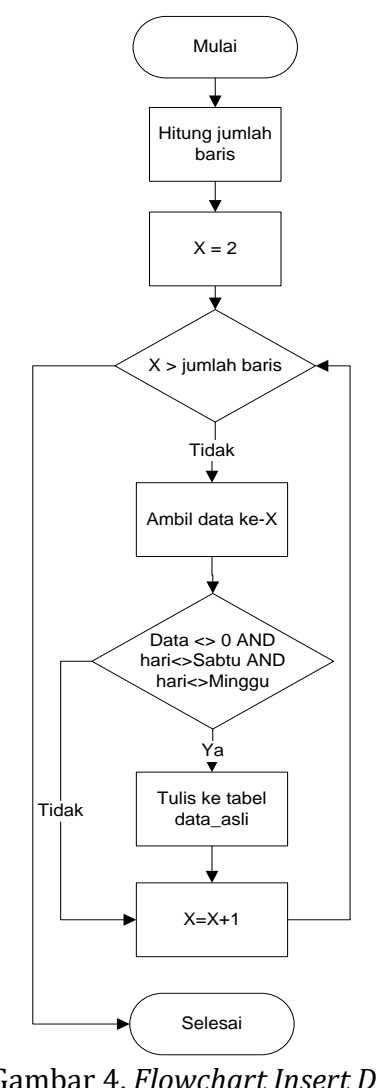

IMPLEMENTASI DAN PEMBAHASAN

\section{Data dan Sumber Data}

Data yang digunakan dalam penelitian ini adalah yang didapat dari situs www.investing.com [3], dan yang digunakan yaitu tanggal, harga (close, open, high, low), range pergerakan mata uang antara Poundsterling terhadap Dollar Amerika (GBPUSD), pada kurun waktu 11 Desember 2015 sampai dengan 28 Februari 2019 dengan periode waktu 1 hari (time frame 1D/Daily). Data yang digunakan memiliki format xls. Contoh data sebagian dapat dilihat pada Tabel 5.

Tabel 5. Data yang digunakan

\begin{tabular}{c|c|c|c|c|c}
\hline Date & Price & Open & High & Low & Range \\
\hline 11 Desember 2015 & 1,5217 & 1,5162 & 1,5240 & 1,5126 & 0,0055 \\
\hline 14 Desember 2015 & 1,5142 & 1,5217 & 1,5232 & 1,5107 & $-0,0075$ \\
\hline 15 Desember 2015 & 1,5035 & 1,5142 & 1,5186 & 1,5026 & $-0,0107$ \\
\hline 16 Desember 2015 & 1,5004 & 1,5038 & 1,5101 & 1,4966 & $-0,0034$ \\
\hline 17 Desember 2015 & 1,4901 & 1,5000 & 1,5004 & 1,4863 & $-0,0099$ \\
\hline
\end{tabular}

\section{Pengujian Metode}

Pada metode Naïve Bayes, untuk memprediksi pergerakan harga forex langkah awal yang dilakukan adalah proses klasifikasi atau menyusun data training berdasarkan kelas, 
disusun dengan 5 input, yaitu dengan nama variabel a, b, c, d, e, dan 2 kelas yaitu, kelas Naik dan Turun. Dalam menyusun 5 input a, b, c, d, e, didapat dari range awal, dimana $\mathrm{x}$ untuk variabel $\mathrm{a}$ $\mathrm{x}+1$ untuk variabel $\mathrm{b}, \mathrm{x}+2$ untuk variabel $\mathrm{c}, \mathrm{x}+3$ untuk variabel $d, x+4$ untuk variabel e, dan $x+5$ untuk menentukan kelasnya. Jika range $x+5$ nilainya lebih besar dari 0 atau bilangan positif, maka akan dimasukkan kedalam kelas Naik, jika lebih kecil dari 0 atau bilangan negative, maka akan dimasukkan ke kelas Turun. Untuk menyusun data uji, prosesnya juga sama, hanya saja sampai $\mathrm{x}+4$. Untuk proses selanjutnya adalah melakukan transformasi data dengan range 0,1-0,9. Tujuan dilakukan transformasi data adalah agar data menjadi berdistribusi normal. Data yang berdistrisbusi normal memiliki ciri yaitu, jika nilai mean lebih besar dari nilai standart deviasinya. Untuk proses transformasi data dapat menggunakan persamaan (1).

dengan:

$$
x^{\prime}=\frac{0,8(x-a)}{b-a}+0,1
$$

$x^{\prime}$ : hasil transformasi

$\mathrm{x}$ : data range awal

a : nilai minimal data range awal

b : nilai maksimal data range awal

Dari data training yang digunakan, didapat nilai minimal data range awal adalah -0,1192 dan nilai maksimal data range awal adalah 0,0369. Maka jika $\mathrm{x}=0,0055$ hitungannya adalah sebagai berikut:

$$
\begin{aligned}
x^{\prime} & =\frac{0,8(0,0055-(-0,1192))}{0,0369-(-0,1192)}+0,1 \\
& =\frac{0,8(0,1247)}{0,1561}+0,1 \\
& =\frac{0,09976}{0,1561}+0,1 \\
& =0,6391+0,1 \\
& =0,7391
\end{aligned}
$$

Selanjutnya adalah mencari nilai mean dan standart deviasi setiap variabel dan berdasarkan kelasnya. Untuk rumus menghitung mean dapat dilihat pada persamaan (2). Untuk menghitung nilai standart deviasi menggunakan persamaan (3).

dengan:

$$
\mu=\frac{x_{1}+x_{2}+x_{3}+\cdots+x_{n}}{n}
$$

$\mu$ : rata-rata hitung (mean)

$x_{i}$ : nilai sample ke- $i$

$\mathrm{n}$ : jumlah sampel

$$
\sigma=\sqrt{\frac{\sum_{i=1}^{n}(x i-\mu)^{2}}{n-1}}
$$

dengan :

$\sigma:$ standart deviasi

$x_{i}$ : nilai $x$ ke- $i$

$\mu$ : rata-rata hitung

$\mathrm{n}$ : jumlah sampel
Setelah menghitung nilai mean dan standart

\begin{tabular}{|c|c|c|}
\hline \multicolumn{3}{|c|}{ Tabel 6. Tabel Nilai } \\
\hline Variabel & Rata-rata & St. Deviasi \\
\hline a (naik) & 0.709575748538 & 0.0388655190564 \\
\hline b (naik) & 0.713665945911 & 0.0397644648468 \\
\hline c (naik) & 0.707964016002 & 0.0485832616361 \\
\hline d (naik) & 0.708180699077 & 0.0506241757643 \\
\hline e (naik) & 0.708382774304 & 0.0365343325919 \\
\hline a (turun) & 0.710535362105 & 0.0503802438451 \\
\hline $\mathrm{b}$ (turun) & 0.706254102218 & 0.0493519824687 \\
\hline $\mathrm{c}$ (turun) & 0.712275568329 & 0.0405594325082 \\
\hline $\mathrm{d}$ (turun) & 0.712380081438 & 0.0380067463902 \\
\hline e (turun) & 0.712285641882 & 0.0521308872123 \\
\hline Nilai & Naik & Turun \\
\hline Jumlah data & 421 & 407 \\
\hline $\begin{array}{c}\text { Probabilitas } \\
\text { setiap fitur }\end{array}$ & 0,508454106 & 0,491545894 \\
\hline
\end{tabular}
deviasi adalah mencari nilai probabilitas setiap fitur pada setiap kelasnya. Untuk mencari nilai probabilitas setiap fitur pada setiap kelas, maka harus menghitung jumlah data kelas yang sama kemudian dibagi dengan jumlah data semua kelas. Dari hitungan yang telah dilakukan, maka didapat hasil yang bisa dilihat pada Tabel 6 .

Langkah selanjutnya adalah mencari nilai probabilitas untuk fitur data uji. Untuk menghitung nilai probabilitas pada fitur data uji dapat menggunakan rumus distribusi Gaussian, untuk rumus dari distribusi Gaussian dapat dilihat pada persamaan 4 .

$$
\mathrm{P}\left(X_{i}=x_{i} \mid Y=y_{j}\right)=\frac{1}{\sigma_{i j} \sqrt{2 \pi}} e^{\frac{-\left(x_{i}-\mu_{i j}\right)^{2}}{2 \sigma_{i j}^{2}}}
$$

dengan:

$\sigma:$ standart deviasi

$\mu$ : rata-rata hitung

$e:$ exponent, memiliki nilai konstan $=2,7183$

$\pi$ : phi, memiliki nilai konstan $=3,14$

$x_{i}$ : nilai $x$ ke- $i$

Pada pembahasan ini, peneliti menggunakan data uji untuk memprediksi tanggal 1 Maret 2019, data uji yang didapat dari penyusunan data yang dilakukan oleh aplikasi dapat dilihat pada Tabel 7

\begin{tabular}{c|c}
\multicolumn{2}{c}{ Tabel 7. Data uji } \\
\hline Variabel & Nilai \\
\hline $\mathrm{a}$ & 0,718577834721 \\
\hline $\mathrm{b}$ & 0,72267777066 \\
\hline $\mathrm{c}$ & 0,789814221653 \\
\hline $\mathrm{d}$ & 0,740102498398 \\
\hline $\mathrm{e}$ & 0,686290839206 \\
\hline
\end{tabular}

Pada persamaan (4), nilai $\mathrm{x}$ didapat dari variabel a, b, c, d, e pada Tabel 7. Untuk nilai mean diambil dari Tabel 6. Nilai Standart Deviasi didapat dari Tabel 6. Untuk menghitung nilai distribusi Gaussian adalah sebagai berikut : $P(a=0,718577834721 \mid$ Naik $)=$ $\frac{1}{\sqrt{2 \pi} * 0.0388655190564} 2,7183 \frac{-(0,718577834721-0.709575748538)^{2}}{2 *(0.0388655190564)^{2}}$

$\frac{1}{0,0974410130335485} 2,7183^{\frac{-(0,00900208618300002)^{2}}{2 * 0,00151052857152339}}$ 


$$
=9,990989
$$

Setelah menghitung nilai distribusi Gaussian dari masing-masing variabel di setiap kelasnya. Didapatlah hasil dari nilai distribusi Gaussian. Pada Tabel 8 adalah tabel yang berisi nilai distribusi Gaussian.

Tabel 8. Nilai Gaussian
\begin{tabular}{|l|l}
\hline Variabel & Gaussian \\
\hline $\mathrm{a}$ (naik) & 9,99099 \\
\hline $\mathrm{b}$ (naik) & 9,7763 \\
\hline $\mathrm{c}$ (naik) & 1,98606 \\
\hline $\mathrm{d}$ (naik) & 6,45838 \\
\hline $\mathrm{e}$ (naik) & 9,09329 \\
\hline $\mathrm{a}$ (turun) & 7,81679 \\
\hline $\mathrm{b}$ (turun) & 7,64662 \\
\hline $\mathrm{c}$ (turun) & 1,58167 \\
\hline $\mathrm{d}$ (turun) & 8,04324 \\
\hline $\mathrm{e}$ (turun) & 6,75669 \\
\hline
\end{tabular}

Selanjutnya, yaitu menghitung probabilitas akhir setiap kelas. Maksudnya adalah mengkalikan semua nilai distribusi Gaussian yang ada ke dalam kelas yang sama. Nilai distribusi Gaussian bisa dilihat pada Tabel 8.

$$
\begin{gathered}
\mathrm{P}(\mathrm{X} \mid \text { Naik })=\mathrm{P}(\mathrm{a}=0,718577834721 / \text { Naik }) \times \mathrm{P}(\mathrm{b}= \\
0,72267777066 \mid \text { Naik }) \times \mathrm{P}(\mathrm{c}= \\
0,789814221653 \mid \text { Naik }) \times \mathrm{P}(\mathrm{d}= \\
0,740102498398 \mid \text { Naik }) \times \mathrm{P}(\mathrm{e}= \\
0,686290839206 \mid \text { Naik }) \\
\mathrm{P}(\mathrm{X} \mid \text { Naik })=9,990989 \times 9,7763 \times 1,98605670535 \\
\mathrm{x} 6,458384946 \times 9,093292486 \\
\mathrm{P}(\mathrm{X} \mid \text { Naik })=11392,5191305245 \\
\mathrm{P}(\mathrm{X} \mid \text { Turun })=\mathrm{P}(\mathrm{a}=0,718577834721 \mid \text { Turun }) \times \\
\mathrm{P}(\mathrm{b}=0,72267777066 \mid \text { Turun }) \times \\
\mathrm{P}(\mathrm{c}=0,789814221653 \mid \text { Turun }) \\
\mathrm{X} \mathrm{P}(\mathrm{d}=0,740102498398 \quad \mid \\
\text { Turun }) \times \mathrm{P}(\mathrm{e}=0,686290839206 \\
\mid \text { Turun }) \\
\mathrm{P}(\mathrm{X} \mid \text { Turun })=7,8167948341 \times 7,6466208906 \times \\
1,5816689677 \quad \mathrm{x} 8,043241827 \quad \mathrm{x} \\
6,75669
\end{gathered}
$$

$\mathrm{P}(\mathrm{X} \mid$ Turun $)=5137,82417056994$

Setelah menghitung nilai probabilitas akhir setiap kelas, maka selanjutnya adalah langkah terakhir yaitu mencari nilai probabilitas akhir. Nilai probabilitas akhir merupakan hasil kali antara nilai probabilitas fitur setiap kelas dan nilai probabilitas akhir setiap kelas. Sehingga hasil yang didapat bisa dilihat pada Tabel 9 .

\begin{tabular}{l|l}
\multicolumn{2}{l}{ Tabel 9. Probabilitas Akhir } \\
\hline $\mathrm{y}$ & $\mathrm{P}(\mathrm{y} \mid \mathrm{X})$ \\
\hline Naik & 5792,57313278864 \\
\hline Turun & 2525,47637369902 \\
\hline
\end{tabular}

Pada tabel 9 telah didapat nilai probabilitas akhir, tetapi diperlukan normalisasi untuk memperoleh nilai sama dengan 1 , dengan cara membagikan nilai probabilitas satu kelas dengan jumlah nilai semua kelas.
$\mathrm{P}($ Naik $)=5792,57313278864 /(5792,57313278864$ $+2525,47637369902)$

$=5792,57313278864 / 8318,04950648766$

$=0,696385989079618$

$\mathrm{P}($ Turun $)=2525,47637369902 /(5792,5731327886$ $4+2525,47637369902)$

$$
\begin{aligned}
& =525,47637369902 / 8318,04950648766 \\
& =0,303614010920382
\end{aligned}
$$

Dari hasil di atas, diubah menjadi prosentase, maka $\mathrm{P}($ Naik) menjadi $70 \%$, dan P(Turun) menjadi 30\%. Jika dilihat dari nilai probabilitas yang sudah dinormalisasi dan dirubah menjadi prosentase, angka terbesar ada di kelas Naik, maka prediksi untuk tanggal 1 Maret 2019 adalah Naik. Untuk pengujian menggunakan aplikasi yang telah dibuat menggunakan data uji sebanyak 20 data yaitu dari tanggal 1 Maret 201928 Maret 2019.

\begin{tabular}{c|c|c|c|c}
\multicolumn{5}{c}{ Tabel 10. Hasil Uji } \\
\hline Tanggal & Real & Prediksi & $\begin{array}{c}\text { Prob } \\
\text { Naik }(\%)\end{array}$ & $\begin{array}{c}\text { Prob } \\
\text { turun }(\%)\end{array}$ \\
\hline 01 Maret 2019 & Turun & Naik & 70 & 30 \\
\hline 04 Maret 2019 & Turun & Naik & 51 & 49 \\
\hline 05 Maret 2019 & Tetap & Turun & 44 & 56 \\
\hline 06 Maret 2019 & Turun & Turun & 44 & 56 \\
\hline 07 Maret 2019 & Turun & Naik & 59 & 41 \\
\hline 08 Maret 2019 & Turun & Turun & 49 & 51 \\
\hline 11 Maret 2019 & Naik & Naik & 59 & 41 \\
\hline 12 Maret 2019 & Turun & Turun & 44 & 56 \\
\hline 13 Maret 2019 & Naik & Naik & 65 & 35 \\
\hline 14 Maret 2019 & Turun & Turun & 4 & 96 \\
\hline 15 Maret 2019 & Naik & Naik & 91 & 9 \\
\hline 18 Maret 2019 & Turun & Naik & 73 & 27 \\
\hline 19 Maret 2019 & Naik & Turun & 30 & 70 \\
\hline 20 Maret 2019 & Turun & Turun & 7 & 93 \\
\hline 21 Maret 2019 & Turun & Naik & 50,2 & 49,8 \\
\hline 22 Maret 2019 & Naik & Naik & 54 & 46 \\
\hline 25 Maret 2019 & Naik & Naik & 57 & 43 \\
\hline 26 Maret 2019 & Naik & Naik & 67 & 33 \\
\hline 27 Maret 2019 & Turun & Turun & 49,4 & 50,6 \\
\hline 28 Maret 2019 & Turun & Turun & 49,7 & 50,2 \\
\hline
\end{tabular}

Dari beberapa percobaan yang dilakukan pada tabel hasil uji dengan membatasi probabilitas terbesarnya, maka didapat hasil yang bisa dilihat pada Tabel 11.

Tabel 11. Hasil uji coba

\begin{tabular}{c|c}
\hline $\begin{array}{c}\text { Minimal Probabilitas } \\
(\%)\end{array}$ & $\begin{array}{c}\text { Tingkat Akurasi } \\
(\%)\end{array}$ \\
\hline 50 & 68,42 \\
\hline 55 & 69,23 \\
\hline 60 & 62,5 \\
\hline 65 & 62,5 \\
\hline 70 & 50 \\
\hline 75 & 100 \\
\hline 80 & 100 \\
\hline 85 & 100 \\
\hline 90 & 100 \\
\hline
\end{tabular}

\section{PENUTUP}

Aplikasi ini sudah dapat memprediksi pergerakan harga forex dengan menggunakan 
metode naïve bayes berdasarkan data yang diupload oleh pengguna.

Berdasarkan hasil yang didapat pada Tabel 11, probabilitas terbesar yang memiliki tingkat akurasi tertinggi adalah 75\%, 80\%, 85\%, dan 90\% dengan tingkat akurasi mencapai 100\%. Tetapi jika dilihat isi yang sama dimana probabilitas terbesarnya 91\%, 93\%, 96\%. Maka untuk meminimalisir resiko kerugian dalam trading forex ketika menggunakan aplikasi ini adalah dengan cara hanya open posisi jika probabilitas naik atau turunnya adalah lebih besar sama dengan $91 \%$.

\section{DAFTAR PUSTAKA}

[1] M. A. Billah, "Aplikasi Prediksi Penyelesaian Dompet Kulit Menggunakan Naive Bayes," Universitas Muhammadiyah Sidoarjo: Teknik Informatika, 2016.

[2] M. Guntur, J. Santony, and Yuhandri, "Prediksi Harga Emas dengan Menggunakan Metode Naïve Bayes dalam Investasi untuk Meminimalisasi Resiko," J. RESTI (Rekayasa Sist. dan Teknol. Informasi), vol. 2, no. 1, pp. 354-360, Apr. 2018.

[3] Investing.com, "Data Historis GBP USD Investing.com,” 2019. [Online]. Available: https://id.investing.com/currencies/gbp-usdhistorical-data. [Accessed: 13-Jan-2019].

[4] Andre, "Tutorial Belajar CSS Part 1: Pengertian CSS, Apa yang dimaksud dengan CSS? I Duniailkom," 2013. [Online]. Available: https://www.duniailkom.com/tutorialbelajar-css-part-1-pengertian-css-apa-yangdimaksud-dengan-css/. [Accessed: 13-Jan2019].

[5] Andre, "Tutorial Belajar HTML Dasar Part 1: Pengertian HTML | Duniailkom," 2017. [Online]. Available: https://www.duniailkom.com/belajar-htmlpengertian-html/. [Accessed: 13-Jan-2019].
[6] Exsanudin, "Implementasi jaringan saraf tiruan backpropagation untuk estimasi jumlah produksi gula: Studi kasus PG. Djombang Baru Jombang," Universitas Islam Negeri Maulana Malik Ibrahim: Fakultas Sains dan Teknologi Teknik Informatika, 2014.

[7] L. Saputri, "Implementasi Jaringan Saraf Tiruan Radial Basis Function (RBF) pada Peramalan Foreign Exchange (FOREX)," Universitas Pendidikan Indonesia: Fakultas Pendidikan Matematika dan Ilmu Pengetahuan Alam - Program Studi Ilmu Komputer, 2016.

[8] W. D. Septiani, "Komparasi Metode Klasifikasi Data Mining Algoritma C4.5 dan Naive Bayes untuk Prediksi Penyakit Hepatitis," J. Pilar Nusa Mandiri, vol. 13, no. 1, 2017.

[9] Suyanto, Machine Learning: Tingkat Dasar dan Lanjut. Bandung: Informatika, 2018.

[10] F. E. Rasjid, Bahasa Pemrograman Populer PHP. UBAYA: Direktorat Sistem Informasi Manajemen, 2014.

[11] Herdianto, "Prediksi Kerusakan Motor Induksi Menggunakan Metode Jaringan Saraf Tiruan Backpropagation," Universitas Sumatera Utara: Fakultas Teknik - Teknik Elektro, 2013.

[12] Marikxon, "Apa itu Forex: Pengertian Forex, Fungsi, dan Pelaku Dalam Pasar Forex," 2014. [Online]. Available: https://www.maxmanroe.com/apa-ituforex.html. [Accessed: 13-Jan-2019].

[13] F. Gorunescu, Data Mining: Concepts, Models and Techniques, vol. 12. Berlin, Heidelberg: Springer Berlin Heidelberg, 2011.

[14] IDCloudHost, "Mengenal Pengertian dan Konsep OOP / Object Oriented Programming | IDCloudHost," 2017. [Online]. Available: https://idcloudhost.com/panduan/mengenalpengertian-dan-konsep-oop/. [Accessed: 13Jan-2019]. 